\section{Perceptions of Febrile Illness among Local People Living in Malaria Endemic villages in Central Hill Region of Nepal}

\section{C.B. Budhathoki}

\section{Abstract}

Objective of this paper is to explore the perceptions of febrile illness among people living in malaria endemic areas of hill region. Qualitative data were collected from malaria endemic villages in Mahadevesthan VDC of Kavrepalanchok district through in-depth interviews and focus group discussions. Local people perceive febrile illnesses as common health problem. They classified febrile illnesses into sardi ko jwaro, dokh, lagu/laganiko jwaro and aulo jwaro. Fever occurring after engaging in heavy physical work is described as dagdi. Severe and complicated form of fever is interpreted as dokh in cultural meaning and typhoid as biomedical concept. Febrile illness which does not respond to biomedicine, but it is relieved by traditional ritual healing is labeled as lagani ko jwaro. Malaria fever is locally known as aul or aulo jwaro. People often avoid certain food such as sour curd, meat, egg, oily and spicy food during fever to prevent it from resulting in dokh (complicated fever). Herbal home remedy is rarely used in febrile illness. Now a day, local people interpret dokh as typhoid and aulo as malaria fever and seek medical treatment from local health institutions and private practitioners. Local perceptions of febrile illnesses such as dokh and aulo overlap with the biomedical concepts of typhoid and malaria fever due to interaction with both traditional healers and health care providers.

Keywords: Perceptions, fever, malaria, typhoid, febrile illness

\section{Introduction}

Febrile illness is most common health problem affecting most of the people in developing world where sanitary conditions remain poor. Among febrile illnesses, typhoid and malaria fever are leading causes of illness. Estimation of the global burden of typhoid fever indicated that there are at least 16 million new cases every year with 600,000 deaths (Crump, Luby \& Mintz, 2004). Incidence of typhoid fever in Asian countries such as Pakistan (451/100,000 population) and India (214/100,000 population) is significantly higher than other Asian Countries like China (15/100,000 population) and Vietnam (21/100.000) (Kothari, Pruthi \&Chugh, 2008). Situation of typhoid fever in Nepal may be similar to that of India and Pakistan. Malaria is one of the common febrile illnesses in tropical and sub-tropical regions of the world. It spreads in 107 countries and territories, subtropical regions of five continents. In 2005, it was estimated that some 3.2 billion people lived in areas at risk of malaria transmission and 350-500 million people suffer from clinical malaria annually, causing about two million deaths each year (WHO/RBM/UNICEF, 2005). Malaria fever is one of the major public health problems in Nepal where 74 percent of the total population is at risk of malaria. The incidence of malaria is highest in the Terai with forest ecology and valleys of the inner Terai for centuries (EDCD, 2004). Nepalese people suffer from different types of febrile illnesses including typhoid, malaria, pneumonia and viral fever.

All over the world, people's perceptions and response towards disease vary according to the prevailing context and environment (Williams \& Jones, 2004; Espino et al., 1997; Jayawardene, 1993; Foster and Anderson, 1978). People in different society hold a variety of concepts and beliefs about illness including fever and malaria that vary according to their socioeconomic and cultural context, have direct impact on preventive and treatment seeking behaviour (Heggenhougen, Hackethal \& Vivek, 2003). Traditionally, Terai people in Nepal ascribe malaria illness to many causes: eating fishes or yogurt, sleeping in the midday sun on grassland or under tree shadow, walking through the early morning dews (Skerry, Moran \& Calavan, 1992). Malaria has been known by different local names-Juditap (hot and Chills) and Judi-Bukhar 
(chills and fever) in the Terai region; aulo-jwaro (fever of swampy areas) in inner Terai and kam jwaro (shivering fever) in the hilly region (Rana, 2001). Tribal people in Mandla of Madhya Pradesh call 'fever with shivering and rigor' as attrala, which closely matches with term malaria (Singh et al, 1998). Fever in some parts of Uganda is referred to as omusuja, a term covering a broad symptom complex ranging from 'feeling unwell' to more specific fever conditions (Kengeya-Kayondo et al. 1994). In Tanzania and in the Swahili speaking parts of East Africa, homa (fever) is a widely used illness term as a symptom of almost every illness including malaria. Homa ya malaria or $\mathrm{mbu}$, which is just one among many fevers is used as synonyms for malaria (HausmannMuela et al., 2002; Winch et al., 1996).

A review of social studies on malaria demonstrates that there are different explanatory models/ideas and concepts about the disease in different communities living in malaria endemic regions. These explanations range from individual risk factors to perceptions rooted in the supernatural and modern medicine concepts as well as the influence of services. The people in malaria endemic areas are aware of the symptoms, causation and treatment of malaria. However, local understanding of malaria does not exactly correspond to biomedical nosology. In many countries, severe malaria associated with convulsion is attributed to the belief of supernatural causes (Hasmann-Muela, 2000; Ahorlu et al., 1997, Winch et al. 1996, Mwenesi et al., 1995). Such locally defined illnesses often diverge from the biomedical concept of disease; described in the anthropology literature as the mismatch between emic (local, e.g. community members) and etic (outside, e.g. health staff) perspectives (Hausmann Muela, 2000). In many areas of the world, where several treatments are available, patients ordinarily use multiple sources of health care in a course of febrile illness, whose choice is determined by numerous factors ranging from knowledge/perceptions to socioeconomic condition of the people and functioning of health services. People living in malaria endemic areas of Nepal have their distinct beliefs and perceptions about malaria and other types of febrile illnesses. But local perceptions and practices related to febrile illness including malaria have not been properly studied and documented. After four decades of implementation of malaria control programme, very little is known about local knowledge, belief and practices related to malaria fever (Sherchand et al., 1996). Some socio-medical and anthropological studies of illness and health-seeking behaviour in Nepal highlighted that local residents have different ideas, beliefs and behaviours, which are associated with local culture, caste, ethnicity and access to the modern health services (Stone, 1977; Durkin-Longley, 1984; Justice, 1987; Subedi, 1989; Niraul, 1994; Blaine, 2003). However, these are not related to the febrile illnesses faced by Nepalese people. Therefore, this study aims to explore the perceptions of febrile illness among people living in malaria endemic areas of Kavrepalanchok district.

\section{Methodology}

This study was conducted in Mahadevsthan Village Development Committee (VDC) of Kavrepalanchok district in central hill region of Nepal, which is situated in the eastern part of the Kathmandu valley. Mahadevsthan VDC lies in the north-east part of the district and southwestern part of the Indrawati River, which act as a natural border between Kavrepalanchock and Sindhupalchok. Topographically it is composed of the low land called tar and phat (paddy field) and sloppy terraced land. It is situated between 600 to $1500 \mathrm{~m}$ altitudes. Most people in this VDC are more or less exposed to the risk of malaria. Study area is inhabited by various caste and ethnic groups such as Brahmin/Chhetris (54\%) and indigenous peoples (36\%) such as Danuwar, Tamang, Newar and Dalit (10\%). In terms of economic condition, 30 percent of the total households are very poor, 42 poor and 28 percent medium/better off. Field work was in Judigau, Dhaitar, Pouwa and Gahate villages of the Mahadevsthan from April to November 2004.

Qualitative methods were used to collect and analyze data. Required data were collected through key informant interview, case interview and focus group discussion techniques. Informed consents were obtained from the research participants before initiating data collection process. Scratch field notes and recorded interviews/discussions were transcribed in Nepali and then translated into English. The collected qualitative data were analyzed using thematic approach. Themes and dimensions were 
identified by reading and highlighting transcripts/field notes. Key issues emerged from data were grouped under the identified themes and categories. Themes and concepts emerged from one interview/discussion were compared with other interviews and discussions. Key findings were summerized and appropriate verbatim was selected for preparing this article.

\section{Results}

Fever is the most common illness as well as symptom in rural areas. It is perceived to be influenced by a number of factors. Local people perceived fever as illness induced by several illnesses and conditions such dagdi (exertion), aulo (malaria), dokh (typhoid), flu, throat pain, pneumonia, evil spirits, Nepale deuta, measles, chicken pox, weakness, walking or working for several hours in a hot day.

In Nepali, fever is called jwaro, but some ethnic-indigenous groups use different terms as synonyms of fever or jwaro. The Tamangs of Mahadevsthan use the term 'chhawah' in their dialect. However, almost all villagers understand the Nepalese terminology 'jwaro' and use this word while interacting with health care providers or outsiders. They attempt to put fevers into several categories based on their judgment and past experiences.

\section{Classification of febrile illnesses}

Shardi ko jwaro (common cold/flu): This type of fever is easily recognized by the villagers on the basis of symptoms. If fever is associated with the running nose, sneezing, cough and throat pain, then it is labeled as shardi ko jwaro or Ruga kanso ko jwaro. It is considered as mild and self-limiting type of fever, which recovers itself or from home remedy or self-medication of anti-cold tablets within few days. Getting wet in the rain, moving from a hot climate to warm or vice versa and drinking water of other places or unusual sources are typical of attributed causes of cold and chills. It is considered as non-serious illness as a part of daily life and people continue their routine work.
Dagdi ko jwaro (fevers of exertion): There is a general belief that mild fever may occur after having engaged in hard work or overwork in the paddy field for several days. During the paddy planting and harvesting season, people need to do hard work in the paddy fields from dawn to dusk without getting proper rest. As a result, some suffer from fever and body ache. Fever occurring during or after the planting and harvesting time is perceived to be the result of overwork/exertion and labeled as ordinary fever. Such fever lasts for one night or a day, which may not require treatment. Informants in interviews and participants in group discussions also expressed the similar views. A Danuwar informant described dagdi as:

"We farmers have to carry out hard work in khet bari for several hours in a day. Our clothes get wet with excessive sweating and some portion of the sweat gets back into the body if they remain wet for long hours. Dagdi fever comes if the sweat is soaked into the body. For several years ago dagdi and aulo were considered to be similar kinds of fever".

A Brahmin informant says:

"During the time of paddy planting, we work in khet for the whole day without caring rain and heat of the sun. Working hard in the sun and rain with the wet clothes affects our body and we suffer a kind of mild fever, called dagdi". Other informants and the participants of group discussions expressed similar views about dagdi.

There is a popular belief among the villagers that hard work or heavy work for several hours results in body ache and fever, which tends to limit itself or with a cetamol tablet (popular name for antipyretic tablets, paracetamol), is called dagdi. Persons who are rarely involved in heavy physical work and those who have feeble and weak body are more prone to have dagdi than do other people.

Aulo (malaria): Aulo is another category of febrile illness, which is easily differentiated from other types of fever by the local residents of Mahadevsthan on the basis of symptoms recognition. Fever that comes with headache, chills and shivering on alternate days is called aulo. It mainly troubles the villagers in summer and 
monsoon season. If high fever continues for several days with or without fluctuation of temperature, then it is recognised as dokh or typhoid. The local perception is that dokh/typhoid can occur in any month and season of the year; but aulo mainly occurs in hot and rainy season.

Dokh (typhoid): It is the widely recognised as folk illness among the local residents. It is a severe and complicated condition of febrile illness marked by bad breath, rashes and ulcer in oral cavity, rotten tongue or sore-throat, burning sensation and pain in the chest and abdomen. There is a general restriction that certain foods such as sour, oily and spicy foods, meats and eggs are to be avoided in time of fever. Disobeying this restriction and being careless during the time of fever lead to the condition of dokh. One old Brahmin informant from the well-off section of the community described dokh as follows:

"If you eat curd, mango, jackfruit, sour and spicy food and meat in fever, they affect food pipe and internal organs and then fever is intensified and exacerbated, then it is called dokh bhayo.... then you begin to exhale stink breath, expel yellow rotten cough, and tongue gets rotten which signify that internal organs are being rotten. If dokh badly affects the heart and liver, you may die."

An educated informant commented as:

"Dokh is old and local terminology, which was used to describe the grave or exacerbated condition of febrile illness. Now, we use new term 'typhoid' instead of dokh for the same meaning. Both typhoid and dokh affects internal parts such as stomach and intestine."

All informants of Mahadevsthan VDC agree that dokh and typhoid fever are the same kind of illness. Although people have adopted 'typhoid' as a synonym for dokh, it has a broader meaning that covers febrile illness resulted from infections of throat, pharynx, chest, food canal and intestines, not necessarily due to the infection of Salmonella bacteria in the intestine. Some informants commented that dokh refers to both typhoid and pneumonia. Many residents of Mahdevsthan still use dokh along with typhoid to indicate complicated condition of the fever. They still follow the cultural rules about avoiding certain food during the episodes of fever to prevent from dokh or typhoid.

Lagu/laganiko jwaro (fever due to evil spirits): Some people still hold the traditional belief that fever may be caused by possession of evil spirits including Nepale deuta (god). Illness is called lagu/lagani ko joro when fever is ascribed to evil spirits or evil spirits evoked by witches. Generally, fever is suspected to be the possession of evil spirits when a sick person feels giddiness and vomits, temperature fluctuates irregularly and lower limbs become cold and other upper parts of the body get very hot or vice versa. Only Jhankri/bombo (traditional healers) can recognize laganikojwaro. If the victim vomits immediately after taking medicine and it does not respond to illness, then family members think that it might be due to the/lagani and start approaching the traditional healers. Fever which recovers after having got jharphuk (blowing mantra) ritual by the traditional healers, and then it is called lagani ko jwaro. Such beliefs are more prevalent among the Dalits and indigenous peoples as compared to the Brhamin/Chhetris.

\section{Perceptions of malaria fever}

Peoples of the eastern mid-Hill areas including Kavre have long used the word 'aul'or 'aulo' for febrile illnesses occurring in the lowland areas in hot season. Literally, aulo refers to hot weather of lowland area such as bensi, khoch and Terai areas. They have been aware that hot climate of the lowland areas during summer and monsoon could bring acute febrile illness- aulo. Nepal Malaria Eradication Organization translated the world 'malaria' into 'aulo' which was similar to the term used by the local people of the Hill areas and launched the programme as 'Nepal Aulo Unmulan Karyakram' (Nepal Malaria Eradication Programme). Since then the people of Hill district (Kavre) have been using aulo to describe the condition of malaria.

In Mahadevsthan (Hill), aulo is categorised into normal aulo and kalo-aulo (black aulo, refers to a deadly malaria). In 1998, the villagers heard of kalo-aulo when some villagers suffered from severe form of malaria and a patient died of it. It was introduced into the villages by a person coming from falciparum endemic 
areas of the Terai. Since then, the local health care providers used the term 'kalo-aulo' for falciparum malaria. Now, many villagers have also heard of kalo-aulo that it is more dangerous than normal aulo. A Tamang informant of Gahate said that villagers as well as doctors could not recognize it easily as it does not show clear symptoms of aulo. He further said:

"Shivering fever may not occur in kalo-aulo. Initially, a light fever comes spasmodically like lagani ko joro (fever due to evil spirits). Later on, the victim complains of high fever, severe headache and pain in the neck and back of the body. It cannot be cured by medicine used in normal aulo."

A Brahmin woman of Dhaitar who had kalo-aulo three years back mentioned that the symptoms of kalo-aulo such as loss of appetite, vomiting, backache, pounding headache, vomiting, senselessness, irregular fever and getting half of body cold and another half very hot were similar to the symptoms of folk illness 'lagani ko jwaro'. Initially she and her family members perceived lagani and sought help from traditional healers. Other informants also agreed that symptoms of kalo-aulo are different from normal aulo and difficult to recognize easily. Irregular fluctuation of temperature, hot and cold body, vomiting, fainting and senselessness are often ascribed to evil spirits that require the help of traditional healers. Because of the lack of awareness of severe manifestations of falciparum malaria, the villagers are likely to interpret kalo-aulo as folk malaria in terms of evil spirits and supernatural forces.

An old Tamang informant of the Gahate from the poor household explained:

"Aulo can be easily recognized at the very beginning when it tends to affect us. However, we do not know where it comes from and how it enters the body. When aulo penetrates us, it chills the body and hairs on limbs stand, and when it reaches into the heart, it causes body ache, chills and shivering. The body needs to be covered with two or three blankets/quilts. Despite covering the body with many clothes, chilling and shivering continue until bhungrejoro (high fever) occurs. After an hour, sweating appears like pouring water and the body gets drenched in the pool of sweat. Fever, joint pain and body ache disappear along with the sweating and we feel well. Then we can continue our routine works if we are not weak. Again fever comes in the same way at the same time on every second or third or fourth day."

A Danuwar informant of Judiguan explained in similar way. "Before having fever, we feel lethargic and lose appetite and dislike food in the morning, and feel cold and shivering in the afternoon or in the evening. We feel very cold internally that shivers us and our body needs to be wrapped with the quilts and blankets. The body begins to stop shivering as soon as the body temperature increases. After some hours, fever goes itself with sweating. We feel hungry and like to eat food. But such fever comes again the day after next in the same manner in the same time. If not treated, the fever recurs several days, the body becomes weak and skin gets yellow. Such fever is aulo or kamjwaro. Old people still call it 'dagdi' and 'aulo.”

People belonging to different caste, ethnic groups and class clearly explained the cold, hot and sweating stage of clinical malaria. They agree that aulo is characterised by headache, body ache or joint pain, chills and rigor, sweating and fever on every alternate days. The villagers can recognize aulo if there is fever and headache with body shivering on every second or third day. All caste and ethnic groups use the term aulo to indicate malaria and its symptoms. However, the Tamangs use slightly different terminology for febrile illnesses such as dokh taba for dokh or typhoid and aulo chhawah for aulo fever, hanga chhawah for shivering fever. They speak using their local terms while interacting among themselves and use aulo jwaro while communicating with outsiders. Local people also mentioned that aulo could be recognised without blood test when a person suffers from headache, joint pain/ body ache, chills/rigor and shivering fever.

Traditionally, people in the Terai as well as in the Hill were not aware of the relation between mosquito and malaria/aulo. There was a perception that hot weather could bring fever associated with 
headache, shivering fever, vomiting and enlarged belly, and yellowish skin. Bensi/tars (lowland areas) of Kavre have been plagued by aulo for centuries. In Mahadevsthan, Brahmin/Chhetris did not settle permanently in the tar and bensi due to fear of aulo (malaria) before the initiation of Malaria Eradication Programme in 1959. During summer and monsoon, they used to move in farmland of tar/bensi in the morning and go back to the permanent houses located uphill areas in the evening. There is common saying that one who stayed one night in tar/bensi or even slept on daytime in the tar/bensi or under the shade of the sal trees could be afflicted with aulo. Sal species (Shoria robusta) are timber plants, which are found in the lower elevation below 1000 above sea level (Paudel, 2003). On local perceptions, ones could get malaria in the low places where the sal trees exist, and there is a relationship between malaria and the sal forest.

There is still a popular belief that living or working in hot place of lowland areas nearby sal forest may cause aulo. An informant of Gahate said:

"We poor people of the Hillock area frequently go to the bensi for working as agricultural labourer in the khet nearby the forest. The heat coming from the forest affects our body and occasionally leads in the condition of aulo."

A Danuwar informant with poor economic background further commented that people living nearby the sal forest could have aulo during summer regardless of use of bedents. Hot and poisonous air coming from the low land areas and sal forest may cause illness and aulo. Local residents still believe that living and working in low places and hot weather around the sal forest increases one's susceptibility to malaria fever. It seems that low-lying place and hot weather is believed to be associated with greater susceptibility to sickness (Blaine, 2003).

An old informant from the well-off stratum commented in such a way:

"Previously, as a dazzling bright and hot haze (rim rim) was seen in the air while seeing distance on sunny days of April and May, our parents used to say that aulo was coming and it could attack us. We were not allowed to sleep or play outside home in the middle of sunny day to protect us from aulo. But these days, we do not care about it. We know that mosquito bites during summer and rainy seasons cause malaria fever."

Villagers still believe that garmi plays an important role in the causation of aulo and living and working in hot season in the low places make ones susceptible to aulo. Discussions with men and women revealed that only living and working around sal trees did not make them vulnerable to aulo; but both garmi (hot) and mosquito bites were responsible for the occurrence of aulo. Educated informants said that malaria fever was culturally believed to be caused by hot weather and working and living around sal forest. Now days, most of the people living in malaria affected areas are aware of the association between mosquito bites and malaria fever. It was mentioned that not using bed nets or failure to use bed nets properly from April to September exposed local people to the risk of malaria fever. There are common perceptions that the temperature, mosquitoes and aulo begin to increase in April along with the fall of yellow leaves of the sal trees, both mosquitoes and aulo decline in the late August and early September, when maize crops get ripe and their stems are removed. Several informants explained that during the hot and rainy season, the density of mosquitoes massively increases, which can bite them outside home as well as inside home. Almost all people in the study areas have heard that mosquito-bites may cause malaria fever; however, they do not adhere only to the biomedical notion of disease causation. Local people often link malaria fever to hot weather, hard work and weakness along with mosquito bites.

\section{Management of febrile illness}

Headache, body ache and fever are self-treated by taking antianalgesic and antipyretic tablets such as paracetamol (locally known as cetamol), which are easily available in tea/retail shop of the village. In case of dagdi fever, people advise sick persons to take bed rest for a day that helps fever limit itself. Informants also reported that paracetamol and ibubrufen (pain killer) tablets are used to relieve body ache, headache and fever. Sometimes hot soup of local chicken is given to the person suffering from dagdi with a view to overcoming weakness. There is common perception that 
dagdi (fever of exertion) recovers itself within a few days without any specific treatment. Therefore, most people initially follow waiting and seeing strategy for a few days before seeking specific treatment of fever.

Local people are aware of avoiding certain food such as sour curd, meat, egg, oily and spicy food during fever to prevent it from resulting into severe illness, called dokh. They usually drink plain hot water or boiled with black pepper or turmeric powder, or ginger and holy basil leaves in fever induced by common cold. In some cases, herbal remedies made of locally available leaves and roots of certain plants are used in dokh. A Danuwar woman said that she prepared juice by crushing roots of archal plant and leaves of bokejhar and fed it to her grandchildren in dokh. Someone who had dokh after having restricted food items during fever needs to be fed a table spoon of ash made by burning the same food items. If one is believed to be suffering from dokh having curds and eggs during fever, s/he should be fed half ounce ash of burnt curd and eggs as folk medicine. It may help to heal dokh. People seek modern medicine from health post and drug retailer when herbal/folk medicine does not work. Now a day, people interpret dokh as typhoid and seek medical help from private practitioners and health institutions.

There is a common perception that fever induced by evil spirits (lagani) cannot be cured by medical treatment. Evil spirits need to be warded off before administering medicine; otherwise, it may not respond to illness or affects the victim adversely. The villagers who belong to the indigenous people stated that when a person presents with high fever or sudden fluctuation of temperature, vomiting, restlessness and speaks senselessly, normally people send him/her first to a traditional healer because they associate these symptoms with lagani, and if injected with a needle or administered medicine, the patient's condition becomes worse. The Brahmin/Chhetri informants who belong to the poor and not-sopoor strata also reasoned that they had not yet abandoned their traditional practice of healing, and initially consulted dhami/Jhankri or Janne Manchhe in many cases and then visited the health care providers. In group discussions, participants expressed similar views that they were following both traditional as well as modern practices of treatment of fever and other illness. But they may not consult the traditional healers in aulo fever which is perceived to be caused by hot weather and mosquito bites.

Local people are well-informed that aulo fever is best treated with anti-malaria tablets (aulo ko chakki) which has been used since the inception of the Malaria Eradication Programme. In case of shivering fever on alternate days, local people often self-diagnose as aulo fever and seek anti-malaria tablets from health post or private drug retailers. Despite the free availability of anti-malaria tablets in the SHP facility, many people prefer to consult drug retailers rather than going to government health facility during fever and malaria. The people of rural areas have three choices: home remedy, traditional ritual healing and biomedical treatment (use of allopathic drugs), which can be used alone or in combination in a single episode of fever according to the condition of the patients and perceived cause of illness. Local people often switch from on treatment modality to another when the first treatment fails to cure illness.

Maya Tamang of Gahate usually had aulo once a year. This year she also suffered from fever, headache and bodyache, and she diagnosed her illness as aulo based on past experiences. On the second day, she went to the SHP to ask for anti-malaria tablets. The SHP staff gave a few tablets of anti-malaria upon her request. But she did not feel well even after having anti-malaria tablets. After one week, she consulted a drug retailer who diagnosed her illness as weakness and typhoid. She was given different tablets, capsule and vitamin syrup. On the next day of this treatment, she became severely ill and senseless for an hour. Then an old bombo (traditional healer) was called at home for traditional healing. Bombo diagnosed she was attacked by different kinds of evil spirits and banjhankri (forest shaman). He performed sick ritual and sacrificed six chickens on three consecutive days. After this, she felt somewhat relieved but continued to have slight fever occasionally for a week. After one month, she completely recovered from fever. She alleged that medicines did not work due to the presence of lagu/lagani. Anti-aulo tablets could have cured her if she had not been attacked by evil spirits. 
Initially, the febrile illnesses are attempted to manage at home by home remedy, self-medication, avoiding, or taking particular food items. Local people consult traditional healers if fever is perceived to be influenced by evil spirits and seek allopathic treatment from health post or drug retailers in typhoid, pneumonia and malaria fever. They know that malaria is best treated with anti-malaria tablets. But herbal remedy or cetamol tablets and traditional ritual healing do not respond to aulo (malaria fever). They also perceive that anti-malaria tablets are antipyretic ones that can treat headache, fever and body ache and they want to have anti-malaria tablets in the perceived aulo fever.

\section{Discussion and Conclusion}

Febrile illness and malaria are well recognised as common problems in study areas. Local people perceive and categorize febrile illnesses into several groups as per their understanding gained from prior experiences, stories from parents, friends and relatives, interaction with health care providers, information from Radio and other media. Febrile illnesses are locally classified into sardi ko jwaro, dokh, lagu/laganiko jwaro and aulo. Severe and complicated form of fever is either interpreted as dokh in cultural meaning and typhoid as biomedical concept. People categorize fever as mild, severe or typhoid, malaria, exertion and evil spirits, which are important for the recognition of illness and malaria as well. Aulo along with kamjwaro is related to the biomedical concept of malaria. According to folk tradition in Sri Lanka, people recognized many febrile illnesses including unahembirissawa (fever and cold), nakahihembirissawa (fever, cough and cold), gahena una (shivering fever), kala una (jungle fever), mura una (fever that recurs at fixed intervals), unasaniptaya (fever caused by upsetting of three humours), sanniya (chill, coma), kolegaya (chest pain) and walippuwa (fits). A folk phrase, gahena una associated with agues was widely used to describe malaria fever as 'shivering fever and vibrating like the coconut flower'. After introduction of western anti-malaria therapy, the local people adopted the new terms 'malariyawa'. In Nepal, these days the folk term aulo is being replaced by the medical word malaria as health care providers use it instead of aulo jwaro.
In Ghana, the local term asra is widely used for fever including malaria (Agyepong, 1992; Ahorlu et al., 1997). Asra is characterized by headache, fever, chills and bitterness of the mouth, yellow eyes, deeply coloured urine, and loss of appetite, body-aches and weakness. Severe and complicated form of asra is called asraku in which a patient becomes very feverish, talk wildly and acts like a madman. People of the Kavrepalanchok hold similar views that a patient suffers from high fever (bhungre jwaro) and sometimes s/he speaks senselessly in complicated and exacerbated fever, dokh. Local perceptions of illness are deeply embedded in their social and cultural belief systems and cultural practices including different health care systems.

Malaria fever is locally known as aul or aulo, which occurs in the lowland areas of Kavrepalanchok in hot season. According to local people's views, aulo fever is characterized by headache, pain in joint, backache, chills, shivering and intermittent fever. They further categorize it into normal aulo (normal malaria) and kaloaulo (dangerous malaria). People's classification of malaria is derived from biomedical notions of malaria such as normal (vivax malaria) and deadly malaria (falciparum). Many people do not view vivax malaria as a severe type of illness and it is placed in the group of routine or mild fevers. Severe malaria is recognised as a degedege characterized by convulsion (Hausmann-Muela, 2000). Similarly, in rural Uganda, malaria is known as omusuja 'folk illness' that covers a broad symptoms including, fever, malaria, feeling unwell and it does not consistently correspond to the clinical case definition of malaria (Kengeya-Kayonda et al., 1994; Nuwaha 2002). Dokh and aulo in Nepal are used in a broader cultural meaning of febrile illness that overlaps with the biomedical concepts of malaria.

Local people have good understanding of malaria symptoms that trigger them to seek treatment from appropriate source. Very highgrade fever, headache and chills (sometimes sweating) are common symptoms of malaria fever recognised by local residents of the study areas (Espino et al., 1997; Agyepong, 1992; Loriosa, 1986). Jayawardene (1993) quoted a narration of one of his informants in Mahaweli Scheme in Sri Lanka as "The fever comes, the fever goes. Suddenly we sweat, feel very cold and the fever 
leaves. You take a Pandol, feel better for a day, fever drops and then it rises. That's malaria” (Jawardene, 1993:1171). Intermittent fever which comes with body shivering and goes after an hour, and again comes next day is recognized as aulo in malaria endemic areas of Kavrepalanchok. Based on symptoms recognition, people could differentiate between malaria and other febrile illnesses. All the villagers irrespective of caste and class are aware of the symptoms of malaria because the people living in malaria endemic areas learn it their own personal experience or other's experiences. The prevalence of disease and past experience of illness are important factors influencing the knowledge of the local residents about symptoms of malaria.

Almost all people in the study areas have heard that mosquito-bites may cause malaria fever; however, they do not adhere only to the biomedical notion of disease causation. Moreover, scientific knowledge about parasites and vectors is very low. The findings of the study indicate that the local residents have multiple notions of malaria causation because their understanding of illness is a synthesis of both traditional and modern concepts. In addition to mosquito-bites, they include hard work and weakness, working or walking out in the sun on extremely hot day and hot weather in malaria causation. Agricultural work during the monsoon season demands high labour forces, most of which are supplied by the family members. At the same time, the incidence of malaria reaches a peak. But some people get confused whether illness is due to malaria or due to overwork and exertion if there are no clear symptoms of malaria. Fever that usually begins with headache and body ache is initially thought to be induced by hard work and exertion.

Other studies have found that people attributed malaria to drinking contaminated water and bathing with dirty water (KengeyaKayondo et al. 1994, Singh et al. 1998, Espino et al. 1997, Loriosa 1986), changing environment and weather (Yadav et al., 1999) and evil spirits and witchcrafts (cf. Hausmann-Muela et al., 2002; Govere et al., 2002; Nuwaha, 2002; Nyamongo, 1998). However, in this study, malaria is not attributed to drinking contaminated water or evil spirits. Only the febrile illness in which fever fluctuate irregularly, patients feel nausea and vomiting or illness which is not cured by allopathic medicine is perceived to be caused by evil spirit. Popular (emic) explanations of illness causation are often overlooked in favour of western health care model that focus on germ theories. In the study areas, people see malaria as a result of mosquito bites, which corresponds to the modern health care model. However, they do not stick to the model of unicausality. Rather they often combine mosquito bites (etic and biomedical concepts) with other contributing factors to account for malaria fever. This broader perception of the causes of malaria among people may probably be due to their perception of malaria as a broader illness term.

Local residents initially use home remedy or antipyretic tablets in normal fevers (flu and dagdi/exertion), consult traditional healers in case of lagu and turn to the drug retailers in the second and third option for fever treatment. In case of aulo (shivering fever), patients visit health posts or drug retailers for getting anti-malaria tablets. Many poor people usually wait at home for a few days whether fever goes without medication. "Waiting and seeing" before seeking modern treatment in febrile illness was mentioned by the villagers in Nepal and it is common in developing countries either due to financial constraints (Asenso-Okyere et al., 1998) or as a tactic in the decision-making process (Ryan, 1998).The villagers prefer modern treatment in several illnesses including malaria fever that belong to the rog/bimar category having naturalistic origin, and use traditional ritual healing services in illnesses perceived to be caused by supernatural forces. There is no exclusive use of traditional healers and home treatment in malaria cases. The local residents admit that the traditional healing rituals cannot cure febrile illness caused by mosquito-bites and hot weather or season change. They seek help from the public and private facilities when they experience the symptoms of malaria. It means that those who have an experience of malaria fever and have capacity of self-diagnosis attend the health care facility as the first help. In contrast, the review of literature shows that one third to half of illnesses are self-treated with anti-malaria tablets obtained from retail shop/pharmacy in Africa (McCombie, 2002). In Nepal, home management of malaria fever with anti-malaria drugs has not been promoted. Unlike paracetamol, anti-malaria tablets are not readily available at retail shops of rural areas. 
People's perceptions of febrile illness-malaria are determined by their past experiences, interaction with health care providers and indigenous health care systems. Local perceptions of febrile illnesses such as dokh and aulo overlap with the biomedical concepts of typhoid and malaria because their understandings are derived from the folk theory of febrile illness as well as biomedical views of diseases. Local understanding about the causation transmission may be correlated with level of exposure to the disease, purposive interventions from the outside and socioeconomic condition of people. This indicates that villagers are quite aware of symptoms of the disease, worried about the possible threat and consequences of febrile illness- malaria, and they have positive attitudes towards modern treatment, which may have impact on the preventive and treatment seeking behaviour for malaria fever.

\section{Acknowledgements}

The study was supported by UNDP/World Bank/WHO Special Program for Research and Training in Tropical Diseases (TDR). I am grateful to Professor Imrana Qadeer and Professor K. R. Nayar, Centre of Social Medicine and Community Health of Jawaharlal Nehru University, New Delhi for their valuable guidance. I am indebted to all participants in the focus group discussion and indepth interview, and other community members for their participation in the study.

\section{References}

Agyepong, I.A. (1992). Malaria: Ethnomedical Perceptions and Practice in Adangbe Farming Community and Implications for Control. Social Science and Medicine, 35(2): 131-137. Ahorlu, C.K., Dunyo, S.K., Afari, E.A. Koram, K.A. and

Nkrumah, F. (1997). Malaria-related Beliefs and Behaviour in Southern Ghana: Implications for treatment, Prevention and Control. Tropical Medicine and International Health, 2(5): 488-499.

Asenso-Okyer, W. K. and Dzator, J. A. (1997). Household Cost of
Seeking Malaria Care. A Retrospective Study of two Districts in Ghana. Social Science and Medicine, 45(5): 659-667.

Blaine, D.K. (2003). Ensnared by AIDS: Cultural Contexts of HIV/AIDS in Nepal. Kathmandu: Mandala Book Point.

Crump , J.A. , Luby, S.P. and Mintz, E,D, (2004. ) The global burden of typhoid fever. Bull World Health Organization, 82:346-353.

Durkin-Longley, M. (1984). Multiple Therapeutic Use in Urban Nepal. Social Science and Medicine, 19(8): 867-872.

EDCD (2004). The Annual Internal Assessment of Malaria And Kala-azar Control Activities 2002. Epidemiology and Disease Control Division, (EDCD), DHS, Ministry of Health. Kathmandu

Espino, F., Manderson, L., Acuin, C., Domingo, F. and Ventura, E.

(1997). Perceptions of Malaria in a Low Endemic Area in the Philippines: Transmission and Prevention of Disease. Acta Tropica, 63: 221-239.

Foster, G.M. and Anderson, B.G. (1978). Medical Anthropology. New York: John Wiley and Sons.

Govere, J., Durrheim, D., la Grange, K., Mabuza, A. and Booman,

M. (2000). Community Knowledge and Perceptions about Malaria and Practices Influencing Malaria Control in Mpumalanga Province, South Africa. South African Medical Journal, 90(6): 611-615.

Hausmann-Muela, S., Ribera, J.M., Mushi, A.D. and Tanner, M.

(2002). Medical Syncretism with reference to Malaria in a Tanzanian Community. Social Sciences and Medicine, 55: 403-413.

Heggenhougen, H.K., Hackethal, V. and Vivek, P. (2003). The behavioural and Social Aspects of Malaria and Control. An Introduction and Annotated bibliography. TDR/STR/SEB/Vol/03.1

Jayawardene, R. (1993). Illness Perception: Social Cost and Coping-Strategies of Malaria Cases. Social Science and Medicine, 37 (9): 1169-1176.

Justice, J. (1987). Policies, Plans and People: Foreign Aid and Health Development. Berkeley: University of California Press. 
Kengeya-Kayondo, J.F., Seeley, J.A., Kajura-Banjenja, E., Kabunga, E., Mubiru, E., Sembajja, F., \& Mulder, D.W. (1994).

Recognition, treatment seeking behaviour and perception of cause of malaria among rural women in Uganda. Acta Tropica, 58: 267-273.

Kothari, A., Pruthi, A., \& Chugh, T.D. (2008). The Burden of

Enteric Fever. Journal of Infection in Developing countries, 2008; 2(4): 253-259.

Loriosa, R. T. (1986). Culture, Environment and People's

Perceptions: Consideration in Malaria Control in the Philippines. Southeast Asian Journal of Tropical Medicare and Public Health, 17 (3):361-370.

McCombie, S.C. (2002). Self-treatment for Malaria: the Evidence and Methodological Issues. Health Policy and Planning, 17(4): 333-344.

Mwenesi, M., Harpham, T., Marsh, K. and Snow, R. W. (1995 b). Perceptions of Symptoms of Severe Child-hood Malaria among the Mijikenda and Luo Residents of Coastal Kenya. Journal of Biosocial Science 87 (2): 235 - 244.

Niraula, B.B. (1994). Use of Health Services in Hill villages in Central Nepal. Health Transition Review, 4: 151-166.

Nuwaha, F. (2002). People's Perception of Malaria in Mbarara, Uganda. Tropical Medicine and International Health, 7(5): 462-470.

Nyamongo, I. K. (1998). Lay people's Responses to Illness: An Ethnographic Study of Anti-malaria Behaviour among the Abagusii of Southwestern Kenya. Ph.D. Dissertation Submitted to the University of Florida.

Poudel, K.P (2003). Watershed Management in the Himalayas: A Resource analysis approach. Delhi: Adroit Publishers.

Rana, K.J (2001). History of Malaria and Malaria Control in Nepal. Kathmandu: Author himself.

Ryan, G.W. (1998). What do Sequential Behavioural Patterns Suggest about the Medical Decision-Making Process: Illness in a Rural Cameroonian Village. Social Science and Medicine, 46(2): 209-225.

Sherchand, J.B., Shrestha, M.P., Hommel, M., Ohara, H., Shrestha, B.L. and Sherchand, S. (1996b). Resurgence of Malaria in Southern Nepal: A Study of Socio-Medical Aspects. Environmental Science , 4(Suppl.): 55-70.
Singh, N., Singh, M.P., Saxena, A., Sharma, V.P., \& Kalra, N.L. (1998). Knowledge, attitude, beliefs and practice (KABP) Study related to malaria and intervention strategies in ethnic tribals of Mandla, Madhya Pradesh. Current Science, 75(12): 13861390.

Skerry, A.C., Moran, K. and Calvan, K.M. (1992). Four Decades of Development: The History of U.S. Assistance to Nepal 1951-1991. Kathmandu: USAID.

Stone, L. (1977): Illness, Hierarchy and Food. Symbolism in Hindu Nepal. Ph.D Thesis, Brown University, USA.

WHO/RMB/UNICEF (2005). World Malaria Report 2005. Geneva: World Health Organisation

Williams, H.A. and Jones, C.O.H. (2004). A Critical Review of Behavioural Issues related to malaria Control in subSaharan Africa: What Contributions have Social Scientists Made? Social Science and Medicine, 59:501-523.

Winch, P.J., Makemba, A. M., Kamazima, S. R., Lurie, M, Luwihula, G. K., Premji, Z., Minjas, J.N. and Shiff, C.J. (1996). Local Terminology for Febrile Illnesses in Bagamoyo District, Tanzania and its Impact on the Design of a Community-Based Malaria Control Programme. Social Science and Medicine, 42(7): 1057-1067.

Yadav, S.P., Tyagi, B.K. and Ramnath, T. (1999). Knowledge, Attitude and Practice towards malaria in Rural Communities of the Epidemic-prone Thar Desert, North Western India. Journal of Communicable Diseases, 31(2): 127-136. 